\title{
Normalization of CALL and TPACK: Discovering Teachers' Opportunities and Challenges
}

\author{
Ramin Rahmany \\ Faculty of Foreign Languages, Islamic Azad University, Takestan Branch, Qazvin, Iran \\ Bahador Sadeghi \\ Islamic Azad University, Takestan Branch, Qazvin, Iran \\ Ali Serdivand Chegini \\ Islamic Azad University, Takestan Branch, Qazvin, Iran
}

\begin{abstract}
The present study aims at investigating the effect of technology integration in general and normalization of CALL in particular on Iranian teachers' technological, pedagogical, and content knowledge (TPACK). It also examines teachers' main opportunities and challenges with normalization of CALL. In this regard, 16 teachers taught a course with the goal to integrate computer technology fully. The researchers implemented a TPACK questionnaire before and after the course and a semi-structured interview after the course. Observations also helped the researchers to gain a complementary understanding of the process of CALL normalization and how teachers deal with their new roles. The results revealed that technology-related knowledge domains developed significantly. The results also showed that Iranian educational society is highly sensitive to instructional technology and its use in education.
\end{abstract}

Index Terms-normalization, technology integration, TPACK

\section{INTRODUCTION}

The full integration of computers into language pedagogy raises the need for a conceptual framework that theorizes the underlying teachers' knowledge. Activities embedded within CALL practice must be built upon a framework of knowledge to result in normalization. Teachers need to grasp the theoretical framework of CALL practice. Regarding the foreign language teaching and learning, CALL research focuses on the ways by which technology shapes learners and helps them move forward in taking hold of the content knowledge. As a leading article, Chambers and Bax (2006) indicated the obstacles to normalization and ways of overcoming them. They clustered those factors into four groups: logistics, stakeholders' conceptions, syllabus and software integration, and training, development and support. Van Olphen (2008) argued for extension of CALL research findings to developing technological content knowledge. In fact, teachers should begin to figure out the great potential of technology to enhance language teaching. Therefore, the present study is focused on an area which is mostly within the domain of teacher's knowledge and practice and aims at finding the relationship between CALL and TPACK development making an attempt to discover teachers' opportunities and challenges. The present study tends to answer the following questions:

1. What is the effect of Normalization of CALL on TPACK and its subdomains including TK, PK, CK, TCK, TPK?

2. What are teachers' opportunities and challenges with technology integration?

A historical portrait of CALL and TPACK research

Technology and its effect on learning has been long matter of debates. Burston (2006) and Mustafa (2001) claimed that there is not enough evidence to prove the efficacy of technology use in learning. On the contrary, many other researchers (Pusack \& Otto, 1997; Alessi \& Trollip, 2001; Dexter, 2002) argued against such statements and supported the use of technology in developing learning processes. But evidently the accelerating pace of technology integration in general and CALL in particular, support their magnificent role in educational context.

To promote the knowledge bases of CALL, it is necessary to reveal the historical background of CALL which goes back about half a century. There are several classifications of CALL, each having special views toward CALL typology, phases of CALL and approaches to CALL (Davies \& Higgins, 1985; Jones \& Fortescue, 1987; Hardisty \& Windeatt, 1989; Warschauer, 1996; Levy, 1997; Warschauer \& Healey 1998; Delcloque, 2000; Warschauer 2000; Jung 2005; and Bax, 2003). Published histories of CALL follow particular lines. Delcloque (2000, p.96) asserts that histories of CALL belong to one of these two categories:

1. "The properly researched, objective historical accounts which attempt to summarize the progression and might include precise dates and a comprehensive list of sources. 
2. The interpretative type which tends to draw more subjective conclusions about advances and trends in the field, thus analyzing its progression in a less objective manner."

\section{Approaches to CALL research}

Generally CALL research is carried out within a polar system; Impact and effectiveness of CALL. Effectiveness focuses on the influence of ICT on improving the approaches and methods of foreign language education in comparison to traditional methods; while impact corresponds with CALL infrastructures, fundamental applications and theoretical bases of use, uptake, access, etc. (Felix, 2005; EACEA, 2009).

\section{CALL impact}

CALL impact measures the broad ideas of CALL in qualitative or quantitative manners. The significance of ICT use and the changes it will add to pedagogy also is covered in this approach. As a good instance of CALL impact, Warschauer and Matuchniak (2010) reviewed studies of the equity in access, use and outcomes of new technologies in U.S society. They found substantial gaps, inequalities and challenges in internet access and claimed that measures of statistical analysis should change. Chapelle $(2004,2005)$ who has a great influence on constructing the underlying concepts of technology use, discussed the impact of technology on posing theoretical, empirical and ethical challenges. He explored the technology-based roles of learner language, interaction, individual differences, linguistic analysis, and language learning and teaching. He concluded in the end that any attempts to research on the use of technology in second language research should consider such crucial challenges (Chapelle, 2004). Elsewhere, he expressed the importance of research into issues of technology implementation in the classroom, students' characteristics that cater to such technologies, and the effectiveness of specific technology-focused or enhanced approaches (Chapelle, 2005). In this case, Kern (2006) also discussed the whys and hows of technology use.

Teacher-related issues are also covered in CALL research domain. Kessler (2007) criticized the lack of formal CALL preparation programs. He stated that many teachers obtain majority of their CALL knowledge via informal channels. In another research on teachers' attitudes toward CALL, surveys and interviews of 83 Iranian high school teachers revealed that lack of time, support, and resources can prevent the use of CALL activities in classrooms (Bordbar, 2010).

\section{CALL effectiveness}

CALL effectiveness has been extensively researched worldwide. Since research design and implementation with this focus are not so tedious, many researchers tend to evaluate the role of computer applications and programs in changing the static conditions of language skills in traditional settings. In a thoroughly organized study, Rezaee and Ahmadzadeh (2012) compared integrated CMC (ICMC), CMC and face-to-face communication on vocabulary improvement among 88 EFL learners. The results showed that ICMC and CMC groups had better performance. It was also implied that ICMC group outperformed CMC. But the important point is that the literature on reading, writing, and spelling is much richer than that of speaking, especially online speaking (Felix, 2008).

\section{Normalization of CALL}

Integrating new technologies into pedagogy has received growing attentions by many researchers and education specialists (Jang, 2008). Two main characteristics of the state of normalization (the ultimate goal of technology integration) which can be figured out in Bax's (2003, 2011) arguments are as follows:

1. The invisibility of technology, especially computer technology, in language classrooms in such a manner that computers are used as inseparable parts of language learning process, like any other regular learning tools, such as pens or books.

2. The decentralization of computers as the only focus of learning. First needs analysis is implemented, and then using -not merely focusing on- computers, needs are met. Computers should place secondary to learning itself.

In addition to what was mentioned, some advantages are considered for the practice of normalization. The most distinguished advantage is the act of clarifying practitioners' goals of CALL integration and obstacles to normalization (Chambers \& Bax, 2006). Other advantages are concerned with researchers. These include the expansion of educational literature and providing space for educational development under the influence of modern innovations.

Chambers and Bax (2006) identified the inhibitive factors to full integration of computers into pedagogy. With the emphasis on sociocultural effects, they clustered them into four sketches as follows:

- Logistics

- Stakeholders' conceptions, knowledge and abilities

- Syllabus and software integration

- Training, development and support

Each of the above issues is subcategorized into a variety of detailed obstacles; though they also claim that some of the obstacles can have local impacts and some can be generalized into any educational environment.

Maftoon and Shahini (2012) in a significant study explored the inhibitive factors to normalization in Iranian contexts. They conducted a survey of 50 in-service teachers and founded that of discouraging factors are ranked as follows:

1. lack of enough facilities

2. lack of administrative support

3. lack of time

4. perceived ease of use

5. low mastery 
6. others' attitude

7. perceived usefulness

The growing desire for integrating new technologies, such as laptops, tablets, cell phones, interactive whiteboard etc. into pedagogy and research into web-based distance learning and virtual learning, extend the domain of CALL dimensions to future world. Cutrim Schmid (2008) studied the potential of interactive whiteboard (IWB) technology for facilitating the normalization of CALL. Emphasizing on teachers' magnificent roles in the process of technology integrating, the findings showed that in spite of the IWB potentials to be integrated into language curriculum, normalization didn't happen successfully, since teachers had misconceptions about the applications of computers.

\section{TPACK research}

The pivotal role of teachers in education and the significance of their knowledge of technology, pedagogy and content gave rise to the notion of teachers' Technological pedagogical and content knowledge known widely as TPACK. On the one hand, considering the new concept of CALL normalization and also other activities within the domain of integrative CALL, a conceptualized framework must theorize the knowledge base used in this cycle. On the other, teaching with educational technology requires that teachers implement complicated knowledge systems. TPACK framework is a response to the lack of theoretical basis for supporting the knowledge for integrating technology into pedagogical content knowledge.

Most of what exist on TPACK results from the analyses and criticisms of Koehler and Mishra's TPACK framework (Mishra \& Koehler, 2006; Koehler \& Mishra, 2008, 2009). Building on Schulman's (1986, 1987) concept of pedagogical content knowledge, a framework for teacher knowledge for technology integration was introduced (Koehler, Mishra, \& Yahya, 2004; Niess, 2005; Mishra \& Koehler, 2006; Mishra, Peruski, \& Koehler, 2007; Koehler \& Mishra, 2009). Technological pedagogical and content knowledge abbreviated to TPCK and afterwards to TPACK (Thompson \& Mishra, 2007) comprises of fundamental knowledge systems. Knowledge of subject matter, general pedagogical strategies and knowledge of technology are the backbones of TPACK framework (Mishra \& Koehler, 2006).

Most of what exists on TPACK results from the analyses and criticisms of Koehler and Mishra's TPACK framework (Mishra \& Koehler, 2006; Koehler \& Mishra, 2008, 2009). Building on Schulman's (1986, 1987) concept of pedagogical content knowledge, a framework for teacher knowledge for technology integration was introduced (Koehler, Mishra, \& Yahya, 2004; Niess, 2005; Mishra \& Koehler, 2006; Mishra, Peruski, \& Koehler, 2007; Koehler \& Mishra, 2009). Technological pedagogical and content knowledge abbreviated to TPCK and afterwards to TPACK (Thompson \& Mishra, 2007) comprises of fundamental knowledge systems. Knowledge of subject matter, general pedagogical strategies and knowledge of technology are the backbones of TPACK framework (Mishra \& Koehler, 2006). In order to provide a mental image of the subdomains that are related to language education (CK, PCK, TCK and TPACK), in the following section we follow a step-by-step description of each knowledge base.

Harris, Mishra and Koehler (2009) analyzed the approaches to technology integration and recommended the flexible and inclusive TPACK framework for technology integration process as the most adequate approach. They also provided evidence that concentrating on TPACK-based activity types develop teachers' effort for technology integration. Harris et al. (2010) described an approach to curriculum-based technology integration namely Grounded technology integration. Using learning activity taxonomies and their subsets (K-6 literacy, mathematics, science, secondary English language arts, social studies, and world languages) they suggested that technology integration is facilitated when teacher knowledge and instructional planning are understood.

Validating, testing and designing statistical instruments to assess the level of TPACK and its components have contributed to a large body of research in many human sciences. Some attempts were made to measure teachers' PCK. Janik, Najvar, Slavic and Trna (2009) aimed at finding the nature of physics teachers' pedagogical content knowledge. Eight lower-secondary school teachers participated in the study. Dynamicity and flexibility were salient characteristics of teachers' emerged PCK. Swan and Hofer (2011) in a study of eight teachers' efforts to integrate podcasting in order to build economic concepts and skills in students reported that through the project teachers developed strong TPK but weak TCK. They concluded that such lacks are rooted in the nature of some digital technologies.

It is worth noting that investigation through the effects of technology integration courses on developing teachers' TPACK provides a suitable ground for teachers to identify the potential challenges in tackling both their professional development issues and the practice of teaching. Although the present study pursues such effects, certainly the results will also reveal parts of the weaknesses and strengths of integration projects.

\section{The CURRENT STUDY}

\section{A. Participants}

Among the total 30 language teachers at the language center, 16 teachers were recruited, including 7 men and 9 women, aged from 21 to 39 , who were teaching to kids, teenagers and adults.

\section{B. Settings and Instrumentation}

In order to gain an adequate control over the process of Normalization, the researchers located a relatively wellequipped language center. The site was equipped with networked computers and a data-projector. 15 computer sets in a 
U-shape layout, connected to a local area network (LAN), the Internet and a data-projector, provided an appropriate condition of physical necessities for moving from CALL activities to non-CALL activities and vice versa (Chambers and Bax, 2006). All computers had appropriate hardware technology, such as a DVD writer, USB ports and earphones. They were customized for high performance. The institution itself exploited necessary equipments like DVD players and televisions. In order to answer the research questions, both qualitative and quantitative instruments were used.

\section{Quantitative instrument}

In order to assess teachers' technological pedagogical and content knowledge, a self-reporting survey which measures teachers TPACK was adopted. Sahin's (2011) Survey of teachers' technological pedagogical and content knowledge is derived from his work with many other researchers to design a survey which is not linked to specific subject area. His survey has many advantages for the present research. The first merit is the process of validity and reliability check. Since the survey items pass clear and precise steps, the results are so trustworthy. The second advantage relates to this point that other questionnaires such as Schmidt et al, (2009) are designed to measure TPACK in specific subject areas and demand a great effort to fit within the framework of other subject areas, which in this regard Sahin's survey excels.

\section{Qualitative instruments}

To monitor the process of normalization and to detect possible deficiencies and obstacles to the process of CALL normalization and also to identify teachers' opportunities and challenges with technology integration, a semi-structured interview was designed. Interviews are often adjoined with survey-based research. They are interactive and allow the researchers to obtain unobservable phenomena (Mackey \& Gass, 2005). Since the present study seeks for teacherrelated issues of CALL normalization; such a flexible data eliciting instrument would help the researchers collect the necessary data. Accordingly, deriving from the results of normalization studies conducted by Chambers and Bax's (2006) four sets of normalization issues and Maftoon and Shahini's (2012) inhibitive factors, the researchers designed a semi-structured interview consisting of 11 guided questions: 3 questions of logistics (No. 1-3), 3 questions of stakeholders' conceptions and support (No. 4-6), 2 questions of syllabus and software integration (No. 7-8), 2 questions of training and ability (No. 9-10) and a question of ranking the most challenging elements (No. 11) (see Appendix A).

\section{Observation}

Due to the vast applications of observation techniques and to provide a complementary attribute to the semistructured interview (Mackey \& Gass, 2005); observation sessions were conducted to monitor students' actions, interactions and teachers' possible challenges during the course.

\section{Method}

Since the process of normalization needs a precise consideration of all related issues, paired sample t-test can show the results accurately. In order to analyze teachers' development of TPACK, a paired sample t-test was conducted. "Paired-sample t-test (also referred to as repeated measures) is used when you have only one group of people (or companies, or machines etc.) and you collect data from them on two different occasions or under two different conditions" (Pallant, 2005, p.209). In order to interpret the effect size for the paired-samples t-test, the eta-squared of the test was calculated using the following formula: Eta squared $=t^{2} / t^{2}+\mathbf{N}-1$

Scripts from semi-structures interviews were analyzed through thematic analysis. The most frequent and similar words and expressions revealed teachers' challenges and opportunities in such courses. Direct observations of these classes helped the researchers scrutinize the contextual issues, mostly student-related issues, for perfect balanced results.

\section{RESULTS}

On the whole, results obtained from the analyses of interviews together with the complementary factors of the observation courses comprised the qualitative analysis. The results of both questionnaire forms and the interviews for TPACK and its subdomains are shown below:

TABLE 1

RESULTS OF QUESTIONNAIRE FORMS AND THE INTERVIEWS

\begin{tabular}{lllllll}
\hline & & Mean & $\mathrm{N}$ & $\begin{array}{l}\text { Std. } \\
\text { Deviation }\end{array}$ & $\begin{array}{l}\text { Std. Error } \\
\text { Mean }\end{array}$ & $\begin{array}{l}\text { Eta } \\
\text { squared }\end{array}$ \\
\hline \multirow{2}{*}{ Pair 1 } & Time 2 TK & 4.7537 & 16 & .12858 & .03214 & 0.93 \\
& Time 1 TK & 4.5338 & 16 & .08342 & .02085 & \\
\multirow{2}{*}{ Pair 2 } & Time 2 PK & 4.1825 & 16 & .10286 & .02571 & \multirow{2}{*}{0.18} \\
& Time 1 PK & 4.1519 & 16 & .11197 & .02799 & \\
Pair 3 & Time 2 CK & 3.9250 & 16 & .22429 & .05607 & \multirow{2}{*}{0.03} \\
& Time 1 CK & 3.9125 & 16 & .20260 & .05065 & \\
Pair 4 & Time 2 TPK & 4.2969 & 16 & .30576 & .07644 & \multirow{2}{*}{0.72} \\
& Time 1 TPK & 4.0156 & 16 & .17002 & .04250 & \\
Pair 5 & Time 2 PCK & 3.8813 & 16 & .27861 & .06965 & \multirow{2}{*}{0.12} \\
& Time 1 PCK & 3.8638 & 16 & .27978 & .06995 & \\
\multirow{2}{*}{ Pair 6 7} & Time 2 TCK & 4.4375 & 16 & .21409 & .05352 & \multirow{2}{*}{0.96} \\
& Time 1 TCK & 3.3281 & 16 & .41552 & .10388 & \\
& Time 2 TPACK & 4.1250 & 16 & .28166 & .07042 & \multirow{2}{*}{0.84} \\
\hline
\end{tabular}


Based on the sections of the interview sections, the qualitative results are divided into five sections as well. Each section follows a special objective around the normalization issues. The first four sections seek to investigate participants' opportunities and challenges during the course. The fifth section ranks the most challenging issues.

\section{Logistics}

Three guided questions (questions no.1 to 3) elicited interviewees' attitudes toward the equipments, practical arrangements, time management and preparations for the course.

Q1: How did you see the facilities of the classroom?

On the one hand, 4 participants claimed that the equipments for such courses should be much more developed. They stated that although they have not been teaching the courses ever before, they feel that running such classrooms demands hi-tech conditions. They talked about utilizing $i$-cam over the projection equipments, through which they could maximize applications of data projectors. They claimed that such technologies can bring the classroom a great deal of change which could undoubtedly lead to students' motivation and success. On the other hand 10 participants asserted that as CALL initiators, but not CALL normalizers, they were satisfied with the equipments and facilities. They added that in spite of the fact that what is really meant by Normalization of CALL, beginning to teach English with available computer technologies can be so remarkable which will consequently found the basis for further facility improvements.

Q2: Did you have enough time to implement what you planned in advance?

Half of the interviewees claimed that in the beginning sessions it was difficult to adjust the lesson and the content within the required time; but gradually after nearly 5 sessions they could manage the content. Others stated that they had no problem with time adjustment.

Q3: How did you prepare yourselffor the classroom?

It was also announced that such classes demand higher preparation than ordinary classes. Eleven teachers stated that they had daily schedules for next day teaching including content review, material preparation, reviewing necessary techniques and sometimes writing a lesson plan. Others told us that they needed no special out-of-the-classroom preparation for teaching; recesses and break times provided the ideal preparation opportunities for them. Our observations revealed that normally those who had scheduled preparation before the classes could better manage the time and the content. Almost all those who had scheduled preparation had fewer problems with class arrangement and time management. Although it's clear that programming teaching materials in advance helps teachers run the classroom more easily; sometimes even such a commonplace situation is forgotten. We also found out that U-shaped arrangement for CALL courses could be highly beneficial; since it provides teachers and students with more space for actions and interactions.

\section{Stakeholders' Conceptions and Support}

Four guided questions (questions no.4 to 6) elicited interviewees' attitudes toward stakeholders' conceptions of the course.

Q4: How do you think of integrating technology in teaching English and of your new role?

All of the participants strongly advocated for continuance of the course in next semesters. This showed their eagerness to work in CALL classrooms. They all claimed that computer integration must be an essential part of the syllabus and all other classrooms could be held in the site too; though they would not concealed their disappointment over the development of CALL in public schools. 10 participants were official teachers of the ministry of education and had complaints against the policies of public schools.

In spite of some problems of time adjustment, preparation, technical and general integration issues which were salient in the observations, all of the participants stated that they had no major problem with their new role. They added that such problems are really inevitable and commonplace. Moreover if students are well justified about the problems, no "inconvenience" will occur.

Q5: Did the administration support you with the course in any aspects? If yes; how?

Our observations showed that the administrator of the institute was eagerly trying to assist teachers with their problems as far as he could. Almost all of the participants confirmed the observations and claimed that they could insert their problems with the administrator whenever they wanted. They asserted that overlooking issues of training and ability and logistics, administration challenges would be of highest significance in such situations. In this respect just one of the participants stated that the administration cannot have a remarkable influence on the process of normalization. He added that only in situations where the administrator is more experienced and has a general acceptance among the teachers, his role is magnified.

Q6: Did students welcome technology integration?

As we entered the domain of questions about the level of students' willingness toward technology integration, there appeared a consensus of opinions. Participants claimed that students' involvement and participation in classroom activities, especially in the sessions where conversation activities was targeted, were surprising. Eleven participants asserted that students' low anxiety and growing self confidence is greatly due to the effect of technology integration tasks.

\section{Syllabus and Software Integration}

Two guided questions (questions no.7 to 8) elicited interviewees' attitudes toward syllabus and software integration. 
Q7: How did you benefit from the Internet and English training software programs?

Although it took some time to start to relatively integrate software programs and especially internet tasks, the process indicated acceptable development which seems to be satisfactory for the course. A couple of ELT software programs and internet complementary tasks were available for teachers to benefit from. It was common in the institution that New Interchange and Learn to Speak English software programs were used for listening and conversation tasks. But participants stated that they aimed at utilizing the available software and the internet fully with higher concentration on interactive dimensions. The internet texts and exercises were utilized as complementary sources, especially where textbook topics would not satisfy expected needs. Through the course 3 teachers utilized the online exercises of Learn to Speak English program. They claimed that it was quite odd for students in the beginning but gradually they accustomed to theses exercises and in the end a part of the final exam was designed based on them.

Q8: How do you think of the course syllabus design?

Some stated that comparing to the regular syllabus of the institution, the present syllabus changed a lot. Some others had no special attitude toward the syllabus. On the whole, participants expressed a relative satisfaction with the syllabus integration and rubrics for the course.

Training and Ability

Two guided questions (questions no. 9 and 10) elicited interviewees' attitudes toward training and ability issues.

Q9: Have you ever attended any professional development course of instructional technology? If not, how did you obtain required knowledge for teaching the course?

Professional courses of instructional technology seem to be new specified courses for the field of teaching. Though recent technology courses in our country are directly connected with computer technology. Most of the participants (14) claimed that they had passed formal technology courses. But they claimed that these formal courses at the university wouldn't fulfill the requirements for what they tackle with in today's growing technological developments. Consequently this gap made them attain a great deal of their knowledge of instructional technology through teaching experience, informal conditions and personal interests.

Q10: Did you have any technical issues? If yes, how did you cope with them?

Technical issues were of the most pervasive challenges that participants had through the course. Interviewees stated that they have faced technical problems through the course. For instance one of the teachers stated:

I wanted to play a short movie for the students. I arranged everything in advance and saved the movie on a flash memory. But the next day I couldn't play the movie. I didn't call for assistance since I thought that it would harm my authority in front of the class. That day my schedule was ruined. Afterward I founded out that the flash memory was malfunctioned.

A similar problem happened to another teacher. It coincided with the observation session. She had an audiovisual story on her laptop and wanted to connect it to the data projector. But she couldn't connect it since the laptop and the data projector were incompatible. They stressed that most of these challenges were related to software issues not hardware ones and troubleshooting them requires experience. Our observations also confirmed that Technical issues were the trouble spot. As mentioned earlier, all of the participants had at least one problem with software or hardware. But they agreed that the matter of time or in other words the matter of experience would solve the technical issues.

\section{Ranking the Most Challenging issues}

Q11: How do you rank the above mentioned issues regarding their effect? Why?

Twelve participants ranked technical issues (among training and ability) as it became partly obvious through the discussions, higher than other issues. They announced that since integrating technologies into teaching is a really difficult job, tackling technical issues demand much more profession and energy. Issues of training, ability placed higher than other issues. Other challenges such as administrators' attitudes in stakeholders' conceptions and support (selected by 2 teachers as the most challenging issue) toward technology use and issues of logistics (selected by 2 teachers as the most challenging issue) also were discussed greatly by teachers. The ranking of the most challenging issues and related discussions are provided in table 2.

TABLE 2

RANKS OF THE ISSUES OF NORMALIZATION

\begin{tabular}{lll}
\hline \multirow{2}{*}{ ISSUE } & & RANK \\
\hline \multirow{2}{*}{ Logistics } & equipments & 3 \\
\cline { 2 - 3 } & Time management & 4 \\
\cline { 2 - 3 } Stakeholders' & preparation & 5 \\
Conceptions and & Administrators & 3 \\
\cline { 2 - 3 } Support & Teachers attitudes & 3 \\
\cline { 2 - 3 } Syllabus and Software & Learners' attitudes & 4 \\
\hline Integration & Software/Internet integration & 6 \\
\hline \multirow{2}{*}{ Training and Ability } & Syllabus integration & 7 \\
\cline { 2 - 3 } & Technical issues & 2 \\
\cline { 2 - 3 } & Training issues & 1 \\
\hline
\end{tabular}

\section{DISCUSSION}


The nature of TPACK and its subcategories is truly evident in teaching with technology. The present study aimed at discovering the extent of interactivity between these phenomena under the very special condition of CALL normalization. The results of the TPACK questionnaire and the semi-structured interview are concluded as follows:

Regarding the increase of participants' score from time 1 to time 2 in technological, technological pedagogical, technological content and technological pedagogical content knowledge, it is obvious that the knowledge of technology has a great influence on developing teachers' knowledge in other domains. The results indicated that when technology is integrated into content and pedagogy, it will even make greater progress too. Although other subdomains had progressed, analyses proved that they were not developed significantly. In the present study the extent to which technological knowledge may contribute to push other domains forward is much higher than the effect of other subcategories of TPACK. The reason seems to be connected to the efficiency and the extent of technological supplies in comparison to non-CALL classrooms. This is concordant with participants' dominant view toward the efficiency of technological facilities and the fact that many of the participants had taught integrative courses scarcely ever.

In spite of the extent of participants and administrator's familiarity with the new instructional technology and how they welcomed CALL activities during the course, the results showed that a particular view toward using computers exists among teachers and administrators. Some responses to three questions of the interview (no 4, 10 and 12) included some good evidence for the existence of this view. Responding to question number 4, one of the experienced participants stated:

When computers are not integrated into language teaching process, there is always a pessimistic view toward using computers in language classroom for both sides including administrators and teachers. But when you perform something well enough with computers, ideas change rapidly... and everybody starts talking of computer advantages.

Another participant answered question number 10 in this way:

I have attended some computer-related course outside and I've learned so many things. But colleagues say that these classes cannot provide you with what you wanted. They say that it's waste of money. I think the atmosphere is not really good.

The same participant responded to question no. 12 as follows:

It's really important to know that teachers' performance in such classes is so remarkable. Definitely regarding this project, normalization had a great effect on at least my own knowledge and skills. But I think these classes are not supported well elsewhere; since the view toward technology, its expansion in educational affairs and the effect on learning is not trusted, especially in relation to teachers' performance.

Through selecting the participants for the project, 14 out of total 30 teachers at the institute did not participate in the course. Shortly thereafter it was heard that some anticipated the course being useless. From the above statements and the general view toward technology use in classrooms, it can be argued that there exist partly- but not totally- a pessimistic view toward the effects and results of normalization activities generally and technology use specifically among groups of teachers and administrators which hinders the rapid development of CALL. This is partly because of the influence of cultural stands. Looking at what and how the procedures of official affairs in our country are progressed, discussions over the use of Internet and filtrations, challenges with satellite receivers/programs and limited services on cell phones and the paradoxes between the present conditions and the real capacity of the society of education to welcome new technologies, it can be concluded that such gaps or sensitivities are rooted in cultural differences. Dudley-Evans and St John (1998) provided a definition of culture and recounted some of the total seven dichotomies of cultural approaches (such as universalism and collectivism) in different nations and groups. Likewise in this regard it can be argued that the sensitivity toward the effect of technology is a cultural situation rather than merely educational problems. Therefore cultures may be dichotomized (but with some overlapping zones) to low technology sensitive and high technology sensitive. Here the researchers exclusively enter the area where cultural issues are raised in educational conceptions since this is not a general cultural discussion. Cultures which are low sensitive to technologies may come across fewer culture-dependant technological problems. Of course the point should not be overlooked that one cannot confirm a hundred percent that Iranian culture is highly sensitive to technology use; since the present research study is not so wide to be generalized respecting its cultural findings. But it reveals part of the true that technology use is somehow ill-considered in our country.

One of the main concerns of the present research study was to discover teachers' opportunities and challenges with CALL normalization. According to the results of the subcategories of the questionnaire, the responses to the interview and complementary observations, the following findings are listed:

Technology use in general and Normalization of CALL or computer integration in particular, provide teachers with fresh opportunities for:

- Developing their knowledge bases especially technological knowledge (TK) for optimal utilization of instructional technologies;

- Developing new technology integration techniques;

- Increasing the speed of learning process;

- Evaluating the appropriateness of new technologies to support students' learning;

- Developing class activities and projects involving use of instructional technologies to reach course objectives easily;

- Teaching a subject with different instructional strategies and computer applications and 
- Teaching successfully by combining content, pedagogy, and technology knowledge.

Technology use in general and Normalization of CALL or computer integration in particular, provide teacher with fresh challenges of:

- Preparation for teaching in computer technology integration courses

- Time adjustment

- Changing administration and students' conception of technology integration

- Cultural sensitivities over the utility of new technologies in classroom;

- Professional courses of instructional technology;

- Technical issues respecting software problems and

- The matter of transient policies for technology integration which is due to economical conditions.

The success or failure of normalization projects highly depends on the congruity of all involved elements including teachers' appropriate level of knowledge and abilities in all aspects of technology, pedagogy and content, developed knowledge of integrative knowledge of TPACK, students developing knowledge of technology use and high motivation; administrators support and cooperation where needed, economical and cultural considerations, the presence of new technological facilities, etc.

Generally what Chambers and Bax (2006) stated about the function of normalization in very specific situations, is to some extent in line with what the present project posed. Observations indicated that students and teachers had still problems with some integrative activities. Through observations and interview sessions, teachers implied that the success of the process of normalization was relatively hopeful but not fully accomplished. Although the course met conditions for normalization well, it seems to be far from the ideal situation of CALL classrooms which is depicted in Bax (2003). However considering the local perspectives and parameters, it is obvious that the process was generally successful.

According to observed limitations of the study and the process of research implementation, future researchers can benefit from the recommendations suggested below:

1. Implementing large-scale studies, certainly builds more replicable results. Since applying the process of normalization demands a huge investment, such large scale studies can be merely conducted by the government sector or powerful private sectors.

2. As Pallant (2005) points, considering a control group along with the participants, will definitely remedy the possible deficiencies of paired sample t-test. This kind of improvement to the study also needs more time and effort.

3. Based on the approaches and types of questions of the study, research studies which exclusively focus on some other factors, e.g. demographic feature of the participants, the analysis of variables effect on each other etc are needed.

4. The final recommendation lies with the fact that in addition to many available surveys of TPACK, there exist other forms of instruments including rubrics of lesson plans, interviews, observation protocols; measurements of artifacts and discourse analysis, which if applied together can give more accurate results. The underlying conceptions and methods for each instrument are elaborated in Abbitt's (2011) Measuring Technological Pedagogical Content Knowledge in Preservice Teacher Education: A Review of Current Methods and Instruments.

TPACK framework and its underlying concepts are fully characterizes through situations where the practice of technology integration can reach the ideal position of normalization. In this regard, although Iranian educational society lacks some infrastructures to develop the integration of instructional technology into pedagogy, teachers warmly welcome the change. Yet some sensitivity toward technology use still exists within the educational society. Therefore removing such barriers would definitely provide the educational strand with necessary motives to mutate at higher rates.

\section{APPENDIX. THE SEMI-STRUCTURED INTER VIEW}

1. How did you see the facilities of the classroom?

2. Did you have enough time to implement what you planned in advance?

3. How did you prepare yourself for the classroom?

4. How do think of integrating technology in teaching English and your new role in CALL courses?

5. Did the administration support you with the course in any aspects? If yes, how?

6. Did students welcome technology integration?

7. How did you benefit from the Internet and English training software programs?

8. How do you think of the course syllabus design?

9. Have you ever attended any professional development course of instructional technology? If not, how did you obtain required knowledge for teaching the course?

10. Did you have any technical issues? If yes, how did you cope with them?

11. How do you rank the above mentioned issues regarding their effect? Why?

\section{REFERENCES}

[1] Abbitt, J. (2011). Measuring technological pedagogical content knowledge in preservice teacher education: a review of current methods and instruments. Journal of Research on Technology in Education, 43(4), 281-300.

[2] Alessi, S. \& Trollip, S. (2001). Multimedia for learning methods and development (3rd Ed.). Massachusetts: Allyn and Bacon. 
[3] Bax, S. (2003). CALL - past, present and future. System, 31(1), 13-28.

[4] Bax, S. (2011). Normalisation revisited: the effective use of technology in language education. International Journal of Computer-Assisted Language Learning and Teaching (IJCALLT), 1(2), 1-15

[5] Bordbar, F. (2010). English teachers' attitudes toward computer-assisted language learning. International Journal of Language Studies (IJLS), 4(3), 27-54.

[6] Burston, J. (2006). Measuring Effectiveness. In Donaldson, R.P. \& Haggstrom, M.A. (Eds.). Changing language education through CALL. London: Routledge.

[7] Chambers, A., \& Bax, S. (2006). Making CALL work: Towards normalisation. System, 34, 465-497.

[8] Chapelle, C. (2004). Technology and second language learning: expanding methods and agendas. System, 32 (1), $593-601$.

[9] Chapelle, C. A. (2005). Interactionist SLA theory in CALL research. In J. L. Egbert \& G. M. Petrie (Eds.), CALL research perspectives (pp. 53-64). Mahwah, New Jersey: Lawrence Erlbaum.

[10] Cutrim Schmid, E. (2008). Interactive whiteboards and the normalization of CALL. In R. de Cássia Veiga Marriott \& P. Lupion Torres, Handbook of Research on E-Learning Methodologies for Language Acquisition (pp. 69-83). Hershey, New York.

[11] Davies G. \& Higgins J. (1985). Using computers in language learning: a teacher's guide. London: CILT.

[12] Delcloque, P. (2000). History of CALL. Retrieved 10, June, 2012, from http://www.h istory-of-call.org

[13] Dexter, S. (2002). eTIPs - Educational technology integration and implementation principles [Online]. In P. Rodgers (Ed.). Designing instruction for technology enhanced learning (pp.56-70). New York: Idea Group Publishing. Retrieved June 10, 2012, from http://www.sdexter.net/Vitae/papers/etips.pdf

[14] Dudley-Evans, A., \& St John, M. J. (1998). Developments in English for specific purposes: A multi-disciplinary approach. Cambridge: Cambridge University Press.

[15] Education, Audiovisual and Culture Executive Agency (EACEA) of the European Commission (2009). Study on the impact of ICT and new media on language learning. Retrieved June 10, 2012, from http://eacea.ec.europa.eu/llp/studies/study_impact_ict_new_media_language_learning_en.php.

[16] Felix, U. (2005). Analysing recent CALL effectiveness research-towards a common agenda. Computer Assisted Language Learning, 18(1\& 2), 1-32.

[17] Felix, U. (2008). The unreasonable effectiveness of CALL: What have we learned in two decades of research. ReCALL, 20(2), 141-161.

[18] Hardisty, D. \& Windeatt, S. (1989). CALL. Oxford: Oxford University Press.

[19] Harris, J. B., Mishra, P., \& Koehler, M. (2009). Teachers' technological pedagogical content knowledge: Curriculum-based technology integration reframed. Journal of Research on Technology in Education, 41(4), 393-416.

[20] Harris, J., Hofer, M., Schmidt, D., Blanchard, B., Young, C., Grandgenett, N., \& Van Olphen, M. (2010). "Grounded" technology integration: instructional planning using curriculum-based activity type taxonomies. Journal of Technology and Teacher Education, 18(4), 573-605.

[21] Higgins J. \& Johns T. (1984). Computers in language learning. London: Collins.

[22] Jang, S. J. (2008). The effects of integrating technology, observation and writing into a teacher education method course. Computers \& Education, 50, 853-865.

[23] Janik, T., Najvar, P., Slavik, J., \& Trna, J. (2009). On the dynamic nature of physics teachers' pedagogical content knowledge. ORBIS SCHOLAE, 3(2), 47-62.

[24] Jones, C. \& Fortescue, S. (1987). Using computers in the language classroom. Harlow: Longman.

[25] Jung, U. O. H. (2005). CALL: past, present and future- a bibliometric approach. ReCALL, 17(1), 4-17.

[26] Kern, R. (2006). Perspectives on technology in learning and teaching languages. TESOL QUARTERLY, 4O(1), 183-210.

[27] Kessler, G. (2007). Formal and informal CALL preparation and teacher attitude toward technology. Computer Assisted Language Learning, 20(2), 173-188.

[28] Koehler, M. J., \& Mishra, P. (2008). Introducing TPACK. In AACTE Committee on Innovation \& Technology (Eds.), Handbook of technological pedagogical content knowledge for educators (pp. 3-29). New York: Routledge.

[29] Koehler, M. J., \& Mishra, P. (2009). What is technological pedagogical content knowledge? Contemporary Issues in Technology and Teacher Education, 9(1), 60-70.

[30] Koehler, M. J., Mishra, P. \& Yahya, K. (2004). Content, pedagogy, and technology: Testing a model of technology integration. Paper presented at the annual meeting of the American Educational Research Association.

[31] Levy, M. (1997). Computer-Assisted Language Learning. Now York: Oxford University Press.

[32] Maftoon, P., \& Shahini, A. (2012). CALL normalization: A survey of inhibitive factors. JALT CALL, 8(1), 17-32.

[33] Mishra, P., \& Koehler, M. J. (2006). Technological pedagogical content knowledge: A framework for integrating technology in teacher knowledge. Teachers College Record, 108(6), 1017-1054.

[34] Mishra, P., Peruski, L., \& Koehler, M. (2007). Developing technological pedagogical content knowledge (TPCK) through teaching online. In R. Carlsen, K. McFerrin, J. Price, R. Weber \& D. A. Willis (Eds.), Proceedings of the Society for Information Technology \& Teacher Education: International Conference 2007 (pp. 2208-2213). Chesapeake, VA: AACE.

[35] Mustafa, Z. (2001). Non-Courseware Factors in Using Multimedia in Foreign Language Instruction. Proceedings of the 7th Conference of Pan-Pacific Association of Applied Linguistics, 244-259 [Online]. Retrieved June 10, 2012, from www.paaljapan.org/resources/proceedings/PAAL7/pdfs/22zahra.pdf.

[36] Niess, M. L. (2005). Preparing teachers to teach science and mathematics with technology: developing technology pedagogical content knowledge. Teaching and Teacher Education, 21(5), 509- 523.

[37] Pallant, J. (2005). SPSS survival manual: a step by step guide to data analysis using SPSS. Allen \& Unwin, Sydney.

[38] Pusack, J.P. \& Otto, S.K. (1997). Taking control of multimedia. In M. Bush \& R. Terry (Eds.). Technology-enhanced language learning (pp.1-46). Chicago: National Textbook Company.

[39] Rezaee A. A. \& Ahmadzadeh, S. (2012). Integrating computer mediated with face-to-face communication and EFL learners' vocabulary improvement. Journal of Language Teaching and Research, 3(3), 346-352. 
[40] Sahin, I. (2011). Development of survey of technological pedagogical and content knowledge (TPACK). The Turkish Online Journal of Educational Technology, 10 (1), 97-105.

[41] Schmidt, D., Baran, E., Thompson, A., Mishra, P., Koehler, M., \& Shin, T. (2009). Technological pedagogical content knowledge (TPACK): The development and validation of an assessment instrument for preservice teachers. Journal of Research on Technology in Education, 42(2), 123-149.

[42] Shulman, L. S. (1986). Those who understand: Knowledge growth in teaching. Educational Researcher, 15(2), 4-14.

[43] Shulman, L. S. (1987). Knowledge and teaching: Foundations of the new reform. Harvard Educational Review, 57(1), 1-22.

[44] Swan, K., \& Hofer, M. (2011). In Search of Technological Pedagogical Content Knowledge: Teachers' Initial Foray into Podcasting in Economics. Journal of Research on Technology in Education, 44(1), 75-98.

[45] Thompson, A. \& Mishra, P. (2007). Breaking News: TPCK Becomes TPACK. Journal of Computing in Teacher Education, 24(2), 38-64

[46] Van Olphen, M. (2008). World language teacher education and educational technology: A Look into CK, PCK, and TPCK. Paper presented at the annual meeting of the American Educational Research Association. NY.

[47] Warschauer, M. (1996). Computer-assisted language learning: An introduction. In S. Fotos (Ed.), Multimedia language teaching (pp. 3-20). Tokyo: Logos International. Retrieved June 10, 2012, from http://www.gse.uci.edu/markw/.

[48] Warschauer, M. (2000). The death of cyberspace and the rebirth of CALL. English Teachers' Journal, 53, 61-67.

[49] Warschauer, M., \& Healey, D. (1998). Computers and language learning: An overview. Language Teaching, 31, 57-71.

[50] Warschauer, M., \& Matuchniak, T. (2010). New technology and digital worlds: Analyzing evidence of equity in access, use, and outcomes. Review of Research in Education, 34(1), 179-225.

Ramin Rahmany is an assistant professor in TEFL. He got his PhD from the University of Tehran three years ago. His research interests include language learning and sentence processing.

Bahador Sadeghi, an assistant professor of Applied Linguistics holds a doctorate degree in TEFL from the University of Isfahan, Iran. He also holds three MAs in TEFL, English Translation and International Relations from Tehran Islamic Azad University, Isfahan University and Allameh Tabatabaee University respectively.

He has been lecturing different subjects in TEFL, Translation studies, General English and ESP at several universities in Iran for the last nineteen years. He has both published and presented a number of articles in some international journals and conferences.

Dr. Sadeghi is the co-author and translator of more than ten books from English to Persian. He is also a certified translator to the judiciary power in Iran and he has been, as a simultaneous interpreter, actively involved in many national and international seminars, sport events and tourism projects.

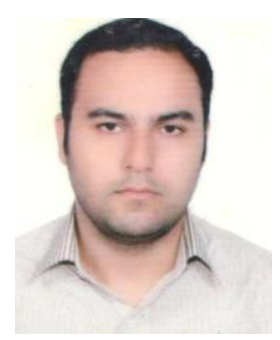

Ali Serdivand Chegini, born in Qazvin/Iran in 1986, is an M.A. graduate in teaching English as a foreign language, from Azad University of Takestan. He completed his M.A. thesis on the relationship between normalization of CALL and technological, pedagogical and content knowledge.

He has been actively involved in translation and teaching English as a school teacher since 2004. He is currently an expert of secondary education department and head of the educational groups in a region of Qazvin. 